primary adrenocortical insufficiency ${ }^{2} 8$ but not for secondary adrenocortical insufficiency because of the possibility of a preserved normal adrenocortical function in secondary insufficiency. Nevertheless, we have recently shown in glucocorticoid-treated patients the value of the simple ACTH stimulation test in assessing the integrated HPA function in secondary insufficiency. ${ }^{3}$

We compared the result of the simple ACTH stimulation test with the HPA response to insulin hypoglycaemia in patients with or without hypothalamic-pituitary disease and varying degrees of adrenocortical insufficiency. A very close correlation was found between the peak plasma cortisol after ACTH and after insulin hypoglycaemia in each patient. It should be emphasised that a patient with borderline results on one test will also have borderline results on the other test, indicating that a borderline ACTH test result should be followed by further evaluation of the HPA function. Our results suggest that a definitely normal response to ACTH is most unlikely to coexist with an impaired response to insulin hypoglycaemia. Examples of such a discrepancy have been reported, ${ }^{2}{ }^{9}$ but information on whether both sweating and low blood glucose values were obtained during insulin hypoglycaemia was not given.

In conclusion, our results suggest that the simple 30-minute ACTH stimulation test is a reliable screening test for impaired HPA function.

\section{References}

1 Jacobs, H S, and Nabarro, J D N, Quarterly fournal of Medicine, 1969, 38, 475.

2 Landon, J, et al, Fournal of Clinical Investigation, 1966, 45, 437

${ }^{3}$ Kehlet, H, and Binder, C, British Medical fournal, 1973, 2, 147.

4 Nielsen, E, and Asfeldt, V H, Scandinavian fournal of Clinical and Laboratory Investigation, 1967, 20, 185.

5 Mortimer, C H, et al, Clinical Endocrinology, 1973, 2, 317.

${ }^{6}$ British Medical fournal, 1970, 1, 644.

7 Speckart, F, Nicoloff, J T, and Bethune, J E, Archives of Internal Medicine, $1971,128,761$

8 Irvine, W J, and Barnes, E W, in Clinics in Endocrinology and Metabolism, ed A S Mason, vol 1, p 549. Philadelphia, 1972

${ }^{9}$ Asfeldt, V H, Acta Medica Scandinavica, 1972, 191, 369.

\title{
Renin concentrations and effects of propranolol and spironolactone in patients with hypertension
}

\author{
BENGT E KARLBERG， BERTIL KÅGEDAL， LENNART TEGLER， KERSTIN TOLAGEN
}

British Medical fournal, 1976, 1, 251-254

\section{Summary}

In a crossover study 32 patients with hypertension were randomly allocated to treatment with spironolactone $200 \mathrm{mg} /$ day for two months, propranolol $320 \mathrm{mg} /$ day for two months, and a combination of both drugs at half the dose. Between the treatments placebo was given for two months. Both spironolactone and propranolol lowered the blood pressure significantly in both positions.

The initial plasma renin activity (PRA) levels ranged from 0.4 to $5.0 \mu \mathrm{g}$ angiotensin $\mathrm{I}^{-1} \mathrm{~h}^{-1}$, and there was a close correlation between these levels and the effects of the drugs: with increasing PRA the response to propranolol was better while the opposite was true for spironolactone. Spironolactone reduced the blood pressure more at eight than at four weeks, while no such difference could be shown for propranolol. Spironolactone and propranolol together decreased the blood pressure still further irrespective of the initial PRA. All patients achieved a normal supine blood pressure.

\footnotetext{
Department of Internal Medicine, University Hospital, S-581 85 Linköping, Sweden

BENGT E KARLBERG, MD, associate professor, endocrine unit

LENNART TEGLER, MD, senior staff physician

KERSTIN TOLAGEN, MD, senior staff physician

Department of Clinical Chemistry, University Hospital, S-581 85 Linkoping, Sweden

BERTIL KÅGEDAL, MD, senior lecturer
}

These results support the concept that the reninangiotensin-aldosterone system may be involved in primary hypertension.

\section{Introduction}

Recently much interest has been focused on the reninangiotensin-aldosterone system and its role in primary (essential) hypertension. ${ }^{1}$ It has been proposed that plasma renin activity (PRA) might have both prognostic ${ }^{2}$ and therapeutic implications. ${ }^{3}$ Bühler et $a l^{3}$ showed that hypertensive patients with normal or high PRA responded more favourably to treatment with beta-adrenergic-blocking drugs, but others-for example, Morgan et $a l^{4}$-could not confirm this. Many studies have verified that low renin hypertension responds best to volumedepleting drugs, such as diuretics or aldosterone antagonists. ${ }^{5-7}$

Our aim was to see whether the response to propranolol or spironolactone was related to the initial PRA. We also wanted to compare the efficacy of propranolol, spironolactone, and the combination of the two drugs in the treatment of primary hypertension.

\section{Patients and methods}

Thirty-two consecutive outpatients with hypertension, 14 men and 18 women ranging in age from 27 to 62 years (mean 46), entered the 10 -month trial. The average known duration of hypertension was 3.4 years (range $0-20$ ); 23 patients had grade I hypertension (World Health Organisation classification) and nine had grade II hypertension. None had eye-ground changes worse than grade II. Nineteen patients had never received antihypertensive treatment, and in the remaining 13 all medication had been withdrawn for at least four weeks. No patients with obstructive lung disease, diabetes mellitus, or hepatic or renal disorder were admitted. None had malignant or secondary 
hypertension. All had a mean untreated blood pressure above $160 / 100$ $\mathrm{mm} \mathrm{Hg}$ supine and standing during the run-in period.

Examination included a 12-lead electrocardiogram, chest $x$-ray examination, and either isotope renography, rapid-sequence intravenous pyelography, or renal arteriography. Urinary adrenaline and noradrenaline levels were measured before treatment. Venous samples for measuring PRA were drawn between 9 am and noon after at least three hours of ambulation. PRA was determined by radioimmunoassay of angiotensin I (AI) according to the method of Haber et $a l^{8}$ with reagents from New England Nuclear Laboratories, but $\mathrm{pH}$ was adjusted to $6 \cdot 0$. The serum and urinary concentrations of sodium and potassium were determined by flame photometry, serum calcium concentrations with a complexometric method, ${ }^{9}$ and serum urea concentrations with a diacetylmonoxime method. ${ }^{10}$ Serum determinations were performed with the SMA 12/60 from Technicon.

Plasma aldosterone levels were determined by a highly sensitive, reproducible, and specific direct radioimmunoassay"1 on the same samples as were used for PRA determinations.

\section{STUDY DESIGN}

Each period consisted of eight weeks of active treatment followed by eight weeks on placebo tablets identical to those containing the previous drug. During the first active period patients received either propranolol $160 \mathrm{mg}$ twice daily (group 1) or spironolactone $100 \mathrm{mg}$ twice daily (group 2). Spironolactone was given in full dose from the beginning, while the dose of propranolol started with $40 \mathrm{mg}$ twice daily and was increased during the first week. After the treatment and subsequent placebo period had been completed for each drug the patients were given combined treatment with half the dose of the two drugs for another two months. The allocation to either treatment was randomised and patients were not aware of the type of treatment given.

Patients were seen every fourth week at the same time of the day (9 am-12 am). Specially trained nurses, unaware of the treatment given, measured blood pressure after 10 minutes of supine rest and after two minutes of standing. A mercury manometer was used in a quiet room and the diastolic pressure registered at the disappearance of the Korotkoff sounds (fifth phase). Blood pressure levels were the mean of at least two recordings and adjusted to the nearest $5 \mathrm{~mm} \mathrm{Hg}$. The regular four-weekly measurements minimised possible changes in laboratory values, particularly PRA, and blood pressure in women with regular menstrual cycles. At each visit the patients were examined by one of us and followed by the same doctor throughout the whole study.

Statistical methods-The Spearman rank test and correlation coefficient were used to evaluate the relation between differences in decreases of blood pressure and the initial PRA levels. ${ }^{12}$ The differences were assumed to be linearly related to the logarithm of initial PRA in order to find the PRA values without significance for the therapeutic response. Regression analysis was then applied. ${ }^{13}$ Student's $t$ test was also used. Values are given as means $\pm \mathrm{SE}$ of mean.

\section{Results}

Twenty-seven patients completed the study. All patients had normal serum potassium levels and normal kidney function. Plasma aldosterone values were normal (137-988 pmol/l (50-356 ng/1)).

\section{BLOOD PRESSURE}

Blood pressures before and during the different treatments are shown in table I. Propranolol for eight weeks reduced the run-in blood pressure by $27 / 18 \mathrm{~mm} \mathrm{Hg}(\mathrm{P}<0 \cdot 001)$ supine and $27 / 15 \mathrm{~mm} \mathrm{Hg}$ $(P<0.01)$ standing. At the end of the following placebo period the mean blood pressure rose to almost pretreatment values. During treatment with spironolactone the blood pressure fell by $33 / 13 \mathrm{~mm} \mathrm{Hg}$ supine and $36 / 12 \mathrm{~mm} \mathrm{Hg}$ standing (both $\mathrm{P}<0.001$ ). At the end of the corresponding placebo period blood pressure again rose to almost pretreatment values. During combined treatment with propranolol and spironolactone blood pressure dropped even further than on either of the two drugs alone. The average drop from pre-treatment levels was $77 / 24 \mathrm{~mm} \mathrm{Hg}$. $(P<0.001)$. Every patient achieved a supine blood pressure of $155 / 100 \mathrm{~mm} \mathrm{Hg}$ or less. There was a significant decrease $(P<0.01)$ of the blood pressure from four to eight weeks on spironolactone. No such effect could be shown for propranolol.

\section{THERAPEUTIC RESPONSE AND INITIAL PRA}

PRA was measured two or three times during the run-in period and the mean of these values was taken as the "initial" PRA. The PRA levels showed good reproducibility before treatment as well as during each treatment for every patient. No correlation of PRA for the urinary sodium excretion seemed justified since urinary sodium ranged from $70 \mathrm{mmol} / 24 \mathrm{~h}$ to $210 \mathrm{mmol} / 24 \mathrm{~h}$, levels that do not influence the PRA levels in the individual patient. The mean sodium excretion and sodium excretion values in each individual patient were fairly constant throughout the study.

There were close relations between the initial PRA and the therapeutic responses to propranolol and spironolactone (see fig). This correlation was significant for systolic and diastolic pressures, both supine and standing. The higher the initial PRA the better the response to propranolol, but the lower the initial PRA the better the response to spironolactone. During propranolol administration the

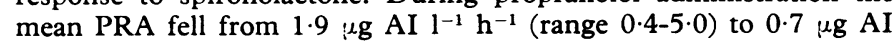

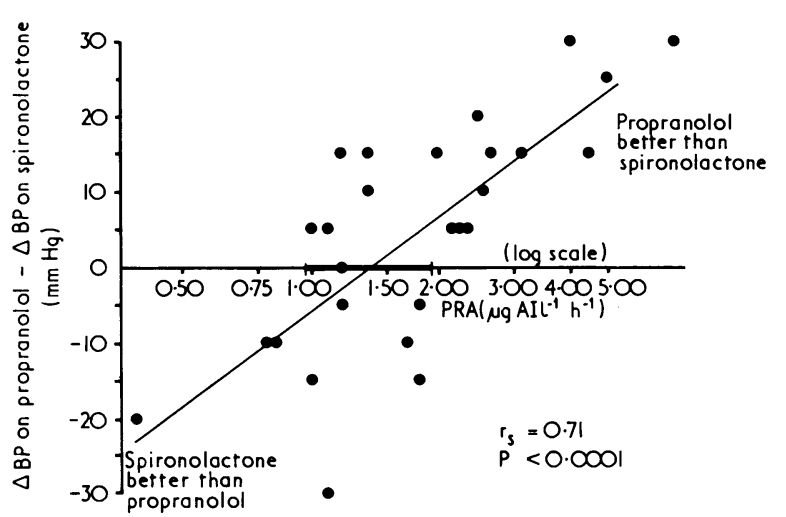

PRA (plotted on logarithmic scale) versus difference in blood pressure reduction with propranolol and spironolactone $(\triangle \mathrm{BP}$ on propranolol $-\triangle$ $\mathrm{BP}$ on spironolactone). Results shown for supine diastolic pressure, but similar results were obtained for all blood pressures measured. At PRA levels $1 \cdot 0-2 \cdot 0 \mu \mathrm{g} \mathrm{AI}^{-1} \mathrm{~h}^{-1}$ no difference in therapeutic response was found between the two drugs. $r_{s}=$ Spearman rank correlation coefficient.

TABLE I-Changes in mean blood pressure $(\mathrm{mm} \mathrm{Hg})$ for all patients throughout study

\begin{tabular}{|c|c|c|c|c|c|c|c|c|c|c|c|}
\hline & \multirow{2}{*}{$\begin{array}{l}\text { Run-in } \\
\text { period }\end{array}$} & \multicolumn{2}{|c|}{ Propranolol } & \multicolumn{2}{|c|}{$\begin{array}{c}\text { Propranolol } \\
\text { placebo }\end{array}$} & \multicolumn{2}{|c|}{ Spironolactone } & \multicolumn{2}{|c|}{$\begin{array}{l}\text { Spironolactone } \\
\text { placebo }\end{array}$} & \multicolumn{2}{|c|}{$\begin{array}{l}\text { Propranolol and } \\
\text { spironolactone }\end{array}$} \\
\hline & & $0-4$ & -8 & -12 & -16 & -20 & -24 & -28 & -32 & -36 & -40 weeks \\
\hline $\begin{array}{l}\text { Supine } \\
\text { Standing }\end{array}$ & $\begin{array}{l}187 / 114 \\
188 / 119\end{array}$ & $\begin{array}{l}162 / 99 \\
162 / 106\end{array}$ & $\begin{array}{l}160 / 96 \\
161 / 104\end{array}$ & $\begin{array}{l}175 / 107 \\
175 / 114\end{array}$ & $\begin{array}{l}182 / 109 \\
187 / 117\end{array}$ & $\begin{array}{l}161 / 103 \\
156 / 107\end{array}$ & $\begin{array}{l}154 / 101 \\
152 / 107\end{array}$ & $\begin{array}{l}169 / 106 \\
168 / 112\end{array}$ & $\begin{array}{l}177 / 108 \\
179 / 115\end{array}$ & $\begin{array}{l}143 / 91 \\
139 / 94\end{array}$ & $\begin{array}{l}143 / 90 \\
141 / 95\end{array}$ \\
\hline
\end{tabular}

TABLE II-Mean ( $\pm S E$ of mean) PRA ( $\left.\mu \mathrm{g} A I l^{-1} h^{-1}\right)$ throughout study in group 1, starting on propranolol, and group 2 , starting on spironolactone

\begin{tabular}{|c|c|c|c|c|c|c|c|c|c|c|c|}
\hline & \multirow{2}{*}{$\begin{array}{c}\text { Run-in } \\
\text { period }\end{array}$} & \multicolumn{2}{|c|}{ Propranolol } & \multicolumn{2}{|c|}{$\begin{array}{l}\text { Propranolol } \\
\text { placebo }\end{array}$} & \multicolumn{2}{|c|}{ Spironolactone } & \multicolumn{2}{|c|}{$\begin{array}{c}\text { Spironolactone } \\
\text { placebo }\end{array}$} & \multicolumn{2}{|c|}{$\begin{array}{c}\text { Propranolol and } \\
\text { spironolactone }\end{array}$} \\
\hline & & $0-4$ & -8 & -12 & -16 & -20 & -24 & -28 & -32 & -36 & -40 weeks \\
\hline Group 1 & $\begin{array}{l}2 \cdot 0 \pm 0.3 \\
1.9 \pm 0.3\end{array}$ & $\begin{array}{l}0.8 \pm 0.2 \\
0.8 \pm 0.1\end{array}$ & $\begin{array}{l}0.9 \pm 0.2 \\
0.5 \pm 0.1\end{array}$ & $\begin{array}{l}1.7 \pm 0.4 \\
2.4 \pm 0.8\end{array}$ & $\begin{array}{l}2 \cdot 1 \pm 0 \cdot 4 \\
1 \cdot 4 \pm 0 \cdot 4\end{array}$ & $\begin{array}{l}6.1 \pm 1 \cdot 2 \\
4.8 \pm 0.7\end{array}$ & $\begin{array}{l}7.3 \pm 1.2 \\
4.9 \pm 0.8\end{array}$ & $\begin{array}{l}3.3 \pm 0.8 \\
1.7 \pm 0.3\end{array}$ & $\begin{array}{l}2.5 \pm 0.7 \\
2 \cdot 1 \pm 0.5\end{array}$ & $\begin{array}{l}3.3 \pm 0.5 \\
2.0 \pm 0.5\end{array}$ & $\begin{array}{l}3 \cdot 4 \pm 0.6 \\
2 \cdot 0 \pm 0.6\end{array}$ \\
\hline
\end{tabular}


TABLE III-Differences in mean serum and urinary electrolytes, serum urea, PRA, and body weight after eight weeks' treatment for whole group compared with pretreatment values

\begin{tabular}{|c|c|c|c|c|c|c|}
\hline \multirow[b]{2}{*}{ Parameter } & \multirow[b]{2}{*}{ Run-in } & \multicolumn{5}{|c|}{ Run-in $v$} \\
\hline & & Propranolol & $\begin{array}{c}\text { Propranolol } \\
\text { placebo }\end{array}$ & Spironolactone & $\begin{array}{c}\text { Spironolactone } \\
\text { placebo }\end{array}$ & $\begin{array}{l}\text { Propranolol and } \\
\text { spironolactone }\end{array}$ \\
\hline $\begin{array}{l}\text { Sodium }(\mathrm{mmol} / \mathrm{l}) \\
\text { Potassium }(\mathrm{mmol} / \mathrm{l}) \\
\text { Urea }(\mathrm{mmol} / \mathrm{l}) \\
\text { Calcium }(\mathrm{mmol} / \mathrm{l}) \\
\text { Urinary sodium }(\mathrm{mmol} / 24 \mathrm{~h}) \\
\text { Urinary potassium }(\mathrm{mmol} / 24 \mathrm{~h}) \\
\text { Body weight }(\mathrm{kg}) \\
\text { PRA }\left(\mu \mathrm{g} \mathrm{AI} \mathrm{l}^{-1} \mathrm{~h}^{-1}\right)\end{array}$ & $\begin{array}{c}142 \cdot 7 \\
4 \cdot 0 \\
4 \cdot 89 \\
2 \cdot 45 \\
142 \\
64 \\
72 \cdot 9 \\
2 \cdot 0\end{array}$ & $\begin{array}{l}-0 \cdot 2 \\
0 \cdot 2 \\
0.64^{*} \\
0 \cdot 025 \\
-8 \\
-2 \\
0 \cdot 6 \\
-1 \cdot 3^{*}\end{array}$ & $\begin{array}{l}-0 \cdot 8 \\
-0.1 \\
-0.21 \\
0.025 \\
9 \\
-1 \\
0 \cdot 4 \\
-0.4\end{array}$ & $\begin{array}{l}-2 \cdot 3^{*} \\
0.5^{*} \\
1 \cdot 23^{*} \\
0 \cdot 05 \\
6 \\
3 \\
-0 \cdot 3 \\
4 \cdot 2^{*}\end{array}$ & $\begin{array}{l}0 \cdot 7 \\
0 \\
0 \cdot 18 \\
0 \cdot 025 \\
4 \\
-5 \\
-0 \cdot 6 \\
-0 \cdot 2\end{array}$ & $\begin{array}{l}-2 \cdot 2^{*} \\
0 \cdot 5^{*} \\
1 \cdot 07^{*} \\
0 \cdot 10^{*} \\
14 \\
2 \\
0 \\
0 \cdot 7\end{array}$ \\
\hline
\end{tabular}

$* \mathrm{P}<0.05$.

Conversion: SI to traditional units-Sodium $1 \mathrm{mmol} / 1=1 \mathrm{mEq} / 1$. Potassium: $1 \mathrm{mmol} / 1=1 \mathrm{mEq} / 1$. Urea: $1 \mathrm{mmol} / 1 \approx 6 \mathrm{mg} / 100 \mathrm{ml}$. Calcium: $1 \mathrm{mmol} / 1 \approx 4 \mathrm{mg} / 100 \mathrm{ml}$.

$1^{-1} \mathrm{~h}^{-1}$ (range $0 \cdot 1-2 \cdot 0$ ), while on spironolactone it rose to $6 \cdot 1 \mu \mathrm{g} \mathrm{AI}$ $1^{-1} \mathrm{~h}^{-1}$ (range $1 \cdot 1-17 \cdot 0$ ) (table II). There was no relation between the degree of change in PRA on either propranolol or spironolactone and the change in blood pressure in the individual patient. A better hypotensive effect by spironolactone could be predicted when PRA

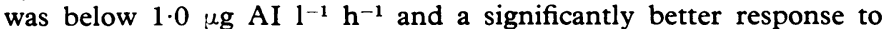
propranolol when PRA was above $2.0 \mu \mathrm{g} \mathrm{AI} 1^{-1} \mathrm{~h}^{-1}$ (see fig).

With increasing age of the patients initial PRA decreased $(P<0.05)$, as has been observed before. ${ }^{1415}$ This might implicate an impaired release of renin because of progressive subclinical renal damage. ${ }^{16}$ No correlation was observed, however, between duration of hypertension and response to the drugs tested.

\section{EFFECTS ON METABOLIC VALUES}

The effects of the different treatments on metabolic values are shown in table III. As expected spironolactone induced an increase in serum potassium and a decrease in serum sodium. Propranolol showed no consistent effects on serum electrolytes. Serum calcium did not change significantly on either drug, but on the combined treatment a slight but significant increase occurred. A small rise in serum urea was observed on all three treatments. Body weight did not change significantly nor did urinary electrolytes.

\section{WITHDRAWALS AND SIDE EFFECTS}

Five patients had to be withdrawn from the study. One patient had a suspected but not verified hypertensive crisis when on propranolol. Another was lost to follow-up when he left the area. One man was excluded because of suspected phaeochromocytoma (occasionally raised levels of urinary catecholamines), which was not verified at surgery. Two patients failed to attend for all examinations.

Both drugs were well tolerated despite the rather high doses given. No patient was withdrawn from the study because of side effects. Those that occurred were of only minor clinical importance on propranolol, insomnia (2), paresthesiae (2), diarrhoea (1), and facial oedema (1); on spironolactone, impotence (2), rash (2), and diarrhoea (1).

\section{Discussion}

Controlled studies comparing propranolol with placebo have included patients with only mild hypertension, ${ }^{17-19}$ and the hypotensive action has sometimes been disappointing. ${ }^{17}$ Our results clearly show that propranolol $320 \mathrm{mg}$ daily alone has a definite hypotensive effect both supine and standing in most patients with primary hypertension. Spironolactone has been reported to lower blood pressure in patients with primary hypertension, ${ }^{20}{ }^{21}$ especially those with primary aldosteronism ${ }^{22}$ or low renin hypertension. ${ }^{23}$ We have confirmed here that spironolactone has a clinically useful antihypertensive effect in hypertensive patients with low and normal PRA.

Both propranolol and spironolactone have a considerable effect on the renin-angiotensin-aldosterone system. ${ }^{24}$ The two drugs act mainly antagonistically on this system: propranolol consistently lowers $\mathrm{PRA}^{25}$ while spironolactone increases it. These effects on PRA are unrelated to the changes in blood pressure.
It has been suggested that constructing profiles of the PRA and aldosterone secretion rate of hypertensive patients might have both prognostic and therapeutic implications. ${ }^{1}$ Although the renin-angiotensin-aldosterone system is known to be implicated in most types of secondary hypertension, its pathogenetic role in primary hypertension remains obscure. ${ }^{24}$

The response to beta-adrenergic blocking drugs has been unrelated to pretreatment PRA levels in some studies. ${ }^{4} 2627$ Bühler $e t a l^{3}$ reported a good response to propranolol in patients with normal or high PRA. They also showed a relation between the decrease of renin and the fall in blood pressure. We observed a significant correlation between the initial PRA and the hypotensive action of propranolol-that is, the higher the PRA the greater the reduction in blood pressure. No such relation could be shown between the decrease in PRA during treatment and the fall in blood pressure, and no difference was found between the blood pressure at four and eight weeks.

In most patients with low-renin hypertension spironolactone has a hypotensive effect. ${ }^{5}{ }^{6}$ It has been argued that spironolactone and diuretics exert comparable actions in these patients. ${ }^{728}$ Spark et $a l^{29}$ showed that spironolactone was more effective than hydrochlorothiazide in low renin hypertension. Brunner et $a l^{2}$ could find no significant effect of propranolol in low-renin hypertension. We have made the same observation in 25 patients with low and non-responsive PRA (unpublished data). Our results showed that spironolactone had a favourable effect at low renin levels, while the opposite was true for propranolol. The blood pressure reductions were well correlated to pretreatment PRA levels. The correlation was validated by the fact that the initial PRA was regained during placebo. Prolonged treatment (more than four weeks) with spironolactone seems necessary to obtain a full effect since blood pressure was lower after eight weeks than after four. It should thus be emphasised that the duration of treatment with spironolactone must be at least eight weeks to evaluate the full hypotensive properties of the drug. We also confirmed that both propranolol and spironolactone were effective in moderate hypertension. Hunyor et al ${ }^{28}$ reported only a slightly hypotensive effect during treatment for one month with spironolactone in very mild hypertension.

A synergistic effect on blood pressure was achieved with the combination of propranolol and spironolactone in only half the doses used in the single drug periods. The additional decrease in blood pressure was obvious and this effect was unrelated to the initial PRA. The combination treatment was well tolerated.

Using PRA concentrations to select the best antihypertensive treatment would be desirable, especially when single-drug treatment is wanted. Nevertheless, the combined treatment gave an excellent antihypertensive effect in all our patients. This indicates that a trial and error management might still be justified.

If PRA cannot be measured routinely we recommend that when the fall in blood pressure is unsatisfactory on a renindepressing beta-blocker-for example, propranolol-a volumedepleting drug such as spironolactone or a thiazide should be used either separately or, if further effect is needed, in combination with propranolol. In the same way, starting with a volume-depleting drug, the pressure effect can be enhanced by 
adding a renin-depressing agent. The range where the pressure effect of the two drugs was uncorrelated to the PRA-levels $\left(1 \cdot 0-2 \cdot 0: \mathrm{g} \mathrm{AI} 1^{-1} \mathrm{~h}^{-1}\right)$ might represent the normal range of PRA.

We conclude from this controlled investigation with propranolol and spironolactone in primary hypertension that both drugs have valuable antihypertensive properties, but their combination results in a further reduction in blood pressure. Our findings also support the concept that patients with high renin concentrations respond more favourably to beta-blocking agents - that is, propranolol - and that those with low renin concentrations respond better to spironolactone. The data also suggest that the renin-angiotensin-aldosterone system may be implicated in primary hypertension.

We thank Mr Bo Bergman for skillful and painstaking statistical aid and Miss Inger Larsson for performing the PRA-determinations.

Propranolol (Inderal), and propranolol placebo tablets were supplied by ICI Pharma AB, Gothenburg, and spironolactone (Aldactone) and spironolactone placebo tablets by G D Searle AB, Malmö, Sweden.

\author{
References \\ ${ }^{1}$ Laragh, J H, American fournal of Medicine, 1973, 55, 261. \\ 2 Brunner, H R, et al, New England fournal of Medicine, 1972, 286, 441. \\ 3 Bühler, F R, et al, New England fournal of Medicine, 1972, 287, 1209. \\ ${ }^{4}$ Morgan, T O, et al, British fournal of Clinical Pharmacology, 1975, 2, 159. \\ ${ }^{5}$ Crane, M G, and Harris, J J, American fournal of Medical Science, 1970, \\ 260, 311 . \\ ${ }^{6}$ Carey, R M, et al, Archives of Internal Medicine, 1972, 130, 849.
}

'Vaughan, E D, et al, American fournal of Cardiology, 1973, 32, 523.

${ }^{8}$ Haber, E, et al, fournal of Clinical Endocrinology, and Metabolism, 1969, 29, 1349.

${ }^{9}$ Gitelman, H J, Analytical Biochemistry, 1967, 18, 520.

${ }^{10}$ Marsh, W H, Fingerhut, B, and Miller, H, Clinical Chemistry, 1965, 11, 624.

${ }^{11}$ McKenzie, J K, and Clements, J A, fournal of Clinical Endocrinology and Metabolism, 1974, 38, 622.

12 Hajek, J, A Course in Nonparametric Statistics. San Francisco, Holden-Day, 1969.

${ }^{13}$ Rao, C R, Linear Statistical Inference and its Applications, p 199. New York, Wiley, 1965.

14 Tuck, M L, et al, American fournal of Cardiology, 1973, 32, 637.

15 Sambhi, M P, Crane, M G, and Genest, J, Annals of Internal Medicine, 1973, 79, 411.

${ }^{16}$ Swales, J D, Lancet, 1975, 1, 75.

17 Paterson, J W, and Dollery, C T, Lancet, 1966, 2, 1148.

${ }_{18}$ Humphreys, G S, and Delvin, D G, British Medical fournal, 1968, 2, 601.

19 Hansson, L, et al, International fournal of Clinical Pharmacology, 1974, $10,79$.

${ }^{20}$ Ogilvie, R I, and Ruedy, J, Canadian Medical Association fournal, 1969, 101,61 .

21 Adlin, E V, Marks, A D, and Channick, B J, Archives of Internal Medicine, 1972, 130, 855.

${ }^{22}$ Ferries, J B, et al, British Medical fournal, 1975, 1, 135.

${ }^{23}$ Dunn, M J, and Tannen, R L, Kidney International, 1974, 5, 317.

24 Oparil, S, and Haber, E, New England fournal of Medicine, 1974, 291, 389.

${ }_{25}$ Michelakis, A M, and McAllister, R G, Fournal of Clinical Endocrinology and Metabolism, 1972, 34, 386.

${ }^{26}$ Hansson, L, and Zweifler, A J, Acta Medica Scandinavica, 1974, 195, 397.

27 Leonetti, G, et al, Clinical Science and Molecular Medicine, 1975, 48, 491.

${ }^{28}$ Hunyor, S N, et al, Australian and New Zealand Fournal of Medicine, 1975, 5,17 .

29 Spark, R F, O'Hara, C M, and Regan, R M, Archives of Internal Medicine, 1974, 133, 205.

\title{
Support for varicose veins
}

\author{
P H FENTEM, MARILYN GODDARD, B A GOODEN
}

British Medical fournal, 1976, 1, 254-256

\section{Summary}

A method has been devised to allow reliable comparison of different strengths and constructions of support hosiery. Five garments were evaluated for the compression they exerted on the leg and their ability to limit the distension of a model varicose vein. Stockings and tights which provide modest compression can achieve worthwhile control of vein distension.

\section{Introduction}

The comfort given by support hosiery, and any possible therapeutic effect on varicose veins is related to the pressure exerted on the legs. ${ }^{1}$ A variety of garments is available, ranging from heavyweight elastic stockings to cosmetically acceptable nylon and elastane hosiery. This study measures the support given by different types of hosiery. Few studies of compression have been undertaken either by manufacturers concerned with establishing the correct design and strength of hosiery ${ }^{2}$ or in the course of clinical studies where it was necessary to describe a particular garment. Meyerowitz and Crook $^{3}$ used a small, airfilled bag to measure, at calf level, the compression provided by one-way stretch elastic stockings. Makin et $a l^{4}$ measured the

Department of Physiology \& Pharmacology, Medical School, University of Nottingham, Nottingham NG7 2 UH

P H FENTEM, MSC, MB, professor of physiology

MARILYN GODDARD, BSC, research assistant

B A GOODEN, MD, lecturer in physiology

pressure exerted on the calf by knee-high Tubigrip elastic stockings using a large polyethylene bag containing saline.

Consideration of the efficacy of different support garments suggested that we needed to study not only the compression exerted on the leg but also the ability of the hosiery to limit the distension of varicose veins. The pressure which a garment exerts on the leg will depend on both its tension and the radius of the limb at a given level. The tension depends on the elasticity of the material and the way it is made. The Laplace relationship states that compression $(\mathbf{P})$ is inversely proportional to radius (R) for a constant rension ( $T)(P=T / R)$. Thus, a decrease in the radius over which the tension of the garment is acting will give an increase in compression. It follows that the compression exerted by hosiery on a distended varicose vein, with a radius of curvature much smaller than that of the whole limb, will be proportionately greater than the compression exerted on the limb at that level. The effect of this compression may be deduced from an examination of the pressure-volume relationship of a varicose vein when it is supported by hosiery, and from measurements of the reduction in volume of blood which collects in varicose veins when they are supported by hosiery and exposed to various distending pressures.

Two methods of measuring support were devised: firstly, compression was measured by a large, flat, liquid-filled bag; secondly, a model varicose vein was constructed so that an estimate of the pressure-volume relationship of a distended superficial vein under hosiery could be made without the difficulties associated with measuring a real vein.

\section{Materials and methods}

Five types of two-way stretch garments were selected for the tests: (a) 250-denier, nylon-covered, elastane support tights; (b) nyloncovered, 0.3-mm rubber core, National Health stockings; (c) 115denier, nylon-covered elastane support stockings; (d) 115-denier, 